\title{
Behavioral Effects of Chronic Fluoxetine in BALB/c Mice Do Not Require Adult Hippocampal Neurogenesis or the Serotonin IA Receptor
}

\author{
Kerri A Holick', Daniel C Lee ${ }^{2}$, René Hen*, ${ }^{*, 2,3}$ and Stephanie C Dulawa ${ }^{2,4}$ \\ 'Department of Pharmacology, Columbia University, New York, NY, USA; ${ }^{2}$ Center for Neurobiology and Behavior, Columbia University, New York, \\ NY, USA; ${ }^{3}$ Department of Psychiatry, Columbia University, New York, NY, USA
}

\begin{abstract}
We previously reported that chronic, but not subchronic, treatment with the selective serotonin reuptake inhibitor (SSRI) fluoxetine altered behavior in the forced swimming test (FST) in BALB/cJ mice. We now use this model to investigate mechanisms underlying the delayed onset of the behavioral response to antidepressants, specifically (I) adult hippocampal neurogenesis and (2) expression of the 5HTIA receptor. Here, we show data validating this model of chronic antidepressant action. We found the FST to be selectively responsive to chronic administration of the SSRI fluoxetine $(18 \mathrm{mg} / \mathrm{kg} /$ day $)$ and the tricyclic antidepressant desipramine $(20 \mathrm{mg} / \mathrm{kg} / \mathrm{day})$, but not to the antipsychotic haloperidol $(\mathrm{Img} / \mathrm{kg} / \mathrm{day})$ in BALB/c mice. The behavioral effects of fluoxetine emerged by 12 days of treatment, and were affected neither by ablation of progenitor cells of the hippocampus nor by genetic deletion of the 5-HTI A receptor. The effect of fluoxetine in the BALB/c) mice was also neurogenesis-independent in the novelty-induced hypophagia test. We also found that chronic fluoxetine does not induce an increase in cell proliferation or the number of young neurons as measured by Brd $U$ and doublecortin immunolabeling, respectively, in BALB/c) mice. These data are in contrast to our previous report using a different strain of mice (I 29SvEvTac). In conclusion, we find that BALB/cJ mice show a robust response to chronic SSRI treatment in the FST, which is not mediated by an increase in new neurons in the hippocampus, and does not require the 5-HTIA receptor. These findings suggest that SSRIs can produce antidepressant-like effects via distinct mechanisms in different mouse strains.

Neuropsychopharmacology (2008) 33, 406-4I7; doi: I0.1038/sj.npp. I30 I399; published online II April 2007
\end{abstract}

Keywords: antidepressant; BALB/c] strain; forced swimming test; neurogenesis; serotonin IA receptor; novelty induced hypophagia

\section{INTRODUCTION}

Selective-serotonin reuptake inhibitors (SSRIs), such as fluoxetine, have emerged as first-line treatments for mood disorders due to an improved side effect profile over tricyclic antidepressants. However, a significant proportion of nonresponsive patients (Kampf-Sherf et al, 2004), and a delay of 2-4 weeks before therapeutic efficacy is apparent (Andreoli et al, 2002; De Nayer et al, 2002; Blier, 2003) impair the treatment of depression. A better understanding of the mechanisms underlying antidepressant efficacy may permit the development of novel treatments with greater efficacy and faster onset.

SSRIs bind the serotonin transporter (SERT) within half an hour after oral administration (Hirano et al, 2005), which

* Correspondence: Professor R Hen, Center for Neurobiology and Behavior, Columbia University, 722 W. I68th St., P.I. Annex 731, I05। Riverside Drive, Unit 87, New York, NY 10032, USA, Tel: + I 212543 5137, Fax: + I 212543 5074, E-mail:rh95@columbia.edu

${ }^{4}$ Current address: Department of Psychiatry, University of Chicago, Chicago, IL, USA.

Received I3 July 2006; revised 14 February 2007; accepted 16 February 2007 is too fast to account for the therapeutic effects that appear weeks later. SSRIs have a net effect of increasing extracellular serotonin (5-HT) concentrations, and this effect accumulates over time with chronic treatment (Kreiss and Lucki, 1995). Therefore, adaptive mechanisms downstream of SERT inhibition likely account for the delayed onset of antidepressant efficacy.

Neurotrophin research (Castren, 2004) has suggested growth-related mechanisms underlying the SSRI response including changes in neurogenesis, and dendritic and spine growth (D'Sa and Duman, 2002; Costa e Silva, 2004). Stress induces dendritic remodeling of CA3 pyramidal neurons, reduces the number of synapses on those neurons, and impairs neurogenesis in the dentate gyrus (Fuchs et al, 2006). While major depression is often thought to be the result of chronic stress, no major cell loss or atrophy in the hippocampus has been found, despite reports of reduced hippocampal volume (Lucassen et al, 2001; Muller et al, 2001).

Many classes of antidepressants have been shown to enhance neurogenesis in the subgranular zone (SGZ) of the hippocampus in rodents (van Praag et al, 1999; Malberg et al, 2000; Scott et al, 2000) reportedly through an increase in the division of amplifying neural progenitor cells 
(Encinas et al, 2006). The time course for integration of new neurons into functional circuits is consistent with the time course for antidepressant drugs to exert therapeutic efficacy (van Praag et al, 2002).

Previously published data (Santarelli et al, 2003) have suggested that hippocampal neurogenesis is required for the behavioral effects of antidepressants in the novelty-suppressed feeding (NSF) and chronic unpredictable stress paradigms. In that study, mice lacking the 5-HT1A receptor (1AKO) did not show the behavioral or neurogenic response to chronic fluoxetine in 129SvEv mice (Santarelli et al, 2003). Fluoxetine-mediated increases in serotonin may stimulate adult hippocampal neurogenesis through 5-HT1A receptor signaling, leading to the behavioral response.

A role of the 5-HT1A receptor in antidepressant efficacy is probable. Chronic antidepressants cause the desensitization of somatodendritic 5-HT1A autoreceptors, removing inhibitory control over the firing rate of serotonergic neurons (Blier et al, 1987; Le Poul et al, 1995; Hensler, 2002; Blier, 2003). Pharmacological studies investigating the role of the 5-HT1A receptor have been inconsistent (Redrobe et al, 1996; Redrobe and Bourin, 1998; Moser and Sanger, 1999), although studies of $1 \mathrm{AKO}$ mice have suggested that this receptor is necessary for the behavioral effects of acute (Mayorga et al, 2001) and chronic (Santarelli et al, 2003) antidepressants.

We previously described behavioral tests of antidepressant action that exhibit sensitivity to chronic, but not subchronic, fluoxetine treatment (Dulawa et al, 2004), and may therefore reflect the therapeutic delay observed in patients. These tests were developed in BALB/cJ mice, which are reported to display high baseline anxiety-like behavior (Robertson, 1979; Belzung and Griebel, 2001; Bouwknecht and Paylor, 2002; Tang et al, 2002). Temporal specificity of antidepressant behavioral effects in the FST have also been reported in $\mathrm{C} 57 \mathrm{Bl} / 6$ mice treated with chronic amitriptyline (21 days, via drinking water) (Caldarone et al, 2003), and in rats treated with fluoxetine via osmotic minipumps (Cryan et al, 2005). However, repeated treatment by daily injection (Reneric et al, 2002) or gavage (Kelliher et al, 2003) in rats showed no difference in the behavioral effects with chronic treatment, although this may be a consequence of the doses studied (Detke et al, 1997).

We used the FST to explore potential underlying mechanisms of the antidepressant response, including adult hippocampal neurogenesis and 5-HT1A receptors. We found that the mouse FST can be used to detect effects of sustained fluoxetine administration beginning at 12 days of treatment, and these effects require neither adult hippocampal neurogenesis nor the 5-HT1A receptor in BALB/cJ mice. In contrast to our previous study (Santarelli et al, 2003), we found the effects of fluoxetine in the BALB/cJ mice in the novelty-induced hypophagia test also to be independent of adult hippocampal neurogenesis, suggesting a strain-specific mechanism of antidepressant efficacy.

\section{MATERIALS AND METHODS}

\section{Animals}

BALB/cJ male mice (Jackson Laboratories, Bar Harbor, ME) were used for pharmacological, time course, and irradiation experiments. Mice arrived at 6-8 weeks of age, and were tested between 12 and 18 weeks of age (25-30 g). Separate groups of mice were used for all drug treatments and time points tested. Additionally, adult male wild-type and 5HT1A receptor null (1AKO) mice were used for separate experiments. All experimental mice were littermates produced from heterozygote breeding. Mice ranged from 2 to 4 months of age, and weighed 18-30 g.

For all experiments, mice were housed five per cage in a colony room controlled for light ( $12 \mathrm{~h}$ light $/ 12 \mathrm{~h}$ dark; on from 0600 to $1800 \mathrm{~h}$ ) and temperature. Food and water were available ad libitum. Behavioral testing occurred during the light phase between 1000 and $1600 \mathrm{~h}$. All animal care and testing conditions were in accordance with the NIH Laboratory Animal Care Guidelines and with IACUC protocol approval.

\section{Drugs}

Fluoxetine (Anawa Biomedical Services and Products, Switzerland), desipramine and haloperidol (Sigma-Aldrich Corporation, St Louis, MO) were made available ad libitum in the drinking water. The concentration of each drug in drinking water was determined from the average daily water consumption ( $x \mathrm{ml} / \mathrm{mouse} / \mathrm{day})$, and the average body weight per mouse (g/mouse) to achieve the desired doses. The drug doses, with the dissolved concentrations in parentheses, were as follows: fluoxetine $18 \mathrm{mg} / \mathrm{kg} / \mathrm{day}$ (160 mg/l), despiramine $20 \mathrm{mg} / \mathrm{kg} /$ day $(240 \mathrm{mg} / \mathrm{l})$, and haloperidol $1 \mathrm{mg} / \mathrm{kg} /$ day $(7.5 \mathrm{mg} / \mathrm{l})$. Drug solutions were protected from light in opaque water bottles. Vehicle-treated animals received regular (tap) drinking water. The drug solutions were replaced every 3 days. Mice treated acutely with diazepam (1.0 and $3.0 \mathrm{mg} / \mathrm{kg}$; Sigma-Aldrich Corporation, St Louis, MO) were administered the drug dissolved in $0.9 \% \mathrm{NaCl}$ and $0.3 \%$ Tween-80 (i.p. injection volume of $10 \mathrm{ml} / \mathrm{kg}$ ) $30 \mathrm{~min}$ before behavioral testing on day 2 of the FST. Each mouse received only one drug and duration of treatment. Plasma levels of fluoxetine, its metabolite norfluoxetine, and desipramine where determined by liquid chromatography with fluorescence detection (Suckow et al, 1992).

In the acute $1 \mathrm{AKO}$ studies, fluoxetine $(10 \mathrm{mg} / \mathrm{kg})$ and desipramine $(20 \mathrm{mg} / \mathrm{kg})$ were dissolved in $0.9 \% \mathrm{NaCl}$ at a volume of $5 \mathrm{ml} / \mathrm{kg}$ of body weight and injected intraperitoneally $30 \mathrm{~min}$ before testing. For chronic studies, the same mice were then chronically administered fluoxetine ( $10 \mathrm{mg} / \mathrm{kg} /$ day) and desipramine $(20 \mathrm{mg} / \mathrm{kg} /$ day $)$ in the drinking water.

\section{Forced Swimming Test}

The test conducted here is a modification of the traditional rat FST (Porsolt et al, 1979), and was performed as we have described previously (Dulawa et al, 2004). Mice are placed into plastic buckets $\left(24^{\prime \prime} \mathrm{h} \times 19^{\prime \prime}\right.$ diam $)$ filled $19^{\prime \prime}$ high with $23-25^{\circ} \mathrm{C}$ tap water for $6 \mathrm{~min}$ each on 2 consecutive days. Both swim sessions are videotaped from a tripod-mounted camera positioned directly above the swim buckets. The swim sessions were analyzed by a blind scorer using a time sampling technique in which the predominant behavior 
(swimming, immobility, or climbing) is scored every $5 \mathrm{~s}$ in the last 4 min of the test (Cryan and Lucki, 2000).

\section{Novelty-Induced Hypophagia}

The novelty-induced hypophagia $(\mathrm{NIH})$ was conducted as described previously (Dulawa et al, 2004). Mice were singly housed, and trained to drink a diluted solution of sweetened condensed milk ( $3: 1$, tap water to milk). Training consists of presenting the milk in a $10 \mathrm{ml}$ serological pipette through the lid of the cage to each mouse for $30 \mathrm{~min}$ per day (days 32-34 of fluoxetine treatment). On the fourth day (day 35), the mice are tested in their home cage for latency to drink the milk and volume consumed over a 30 -min period. On the fifth day (day 36), mice are retested in a novel cage, which has no bedding and is more brightly lit.

\section{Ablation of Progenitor Cells}

All mice were anesthetized with ketamine and xylazine (100 and $7 \mathrm{mg} / \mathrm{kg}$, respectively). Half of the mice ('sham') were then returned to their home cage. The other half of the mice ('X-ray') were irradiated as described previously (Santarelli et al, 2003). After being anesthetized, the X-ray mice were subsequently placed in a stereotaxic frame to position the brain for hippocampal-specific irradiation using a Siemens Stabilopan X-Ray System $(300 \mathrm{kVp}$ and $20 \mathrm{~mA})$. A lead shield was placed over the entire body including the head with a $3.22 \times 11 \mathrm{~mm}$ opening in the shield positioned over the hippocampus. X-ray mice were given $5 \mathrm{~Gy}$ of irradiation on three occasions spaced 3 days apart (total: 15 Gy over 1 week). A dose of $15 \mathrm{~h}$ Gy reduces cell proliferation by at least $85 \%$ in the denate gyrus of the hippocampus using this procedure (Santarelli et al, 2003). Sixty mice were used in this experiment with 15 mice per group by drug (vehicle or fluoxetine) and X-ray (sham or X-ray) condition.

\section{Perfusion and Sectioning}

To assess changes in cell proliferation in the dentate gyrus, 4 days after the completion of behavioral testing, mice were injected once with bromodeoxyuridine $(150 \mathrm{mg} / \mathrm{kg}$, i.p.; Miller and Nowakowski, 1988; Yu et al, 1992). Two hours after injection, mice were anesthetized with ketamine and xylazine (100 and $7 \mathrm{mg} / \mathrm{kg}$, respectively), and killed by cardiac perfusion (4\% paraformaldehyde). Brains were then post-fixed overnight in $4 \%$ paraformaldehyde at $4{ }^{\circ} \mathrm{C}$ then transferred into a $30 \%$ sucrose $/ 0.1 \%$ sodium azide cryoprotectant until the brains sank. Brains were embedded in tissue freezing medium, and sectioned using a cryostat to cut $35 \mu \mathrm{m}$ coronal sections. Sections from each brain were collected to generate six representative sets of each mouse hippocampus. Each set of brains includes twelve $35 \mu \mathrm{m}$ sections through the hippocampus, and was stored in one well of a 24-well plate in phosphate-buffered saline (PBS) with $0.1 \%$ sodium azide at $4{ }^{\circ} \mathrm{C}$.

\section{Bromodeoxyuridine Immunohistochemistry}

Mounted sections were boiled for $5 \mathrm{~min}$ in $0.01 \mathrm{M}$ citric acid (pH 6.0) then rinsed with PBS. Sections were treated with $0.1 \mathrm{M}$ Tris- $\mathrm{Cl} / 0.1 \%$ trypsin $/ 0.1 \% \mathrm{CaCl}_{2}$ for $7 \mathrm{~min}, 2 \mathrm{~N} \mathrm{HCl}$ for $30 \mathrm{~min}$, and then blocked with $3 \%$ normal goat serum $(1 \mathrm{~h})$. Primary antibody (anti-mouse BrdU, 1:100) was applied with overnight incubation. On the following day, sections were washed of primary antibody, and incubated for one hour with goat anti-mouse IgG biotinylated secondary antibody (1:200 in $1.5 \%$ NGS). The signal of the biotinylated secondary antibody was then amplified by binding avidin-biotin complex $(\mathrm{ABC})$, which contains peroxidase. The substrate, diaminobenzidine (DAB) was then applied to visualize the staining by the action of peroxidase on $\mathrm{DAB}$, which produces a visible brown product. Sections were counterstained with Fast Red, dehydrated, delipidated, and coverslipped.

\section{Doublecortin Immunohistochemistry}

To assess expression of doublecortin (DCx), a cellular marker of young neurons (Brown et al, 2003), free-floating sections were treated with $0.3 \%$ peroxidase followed by blocking with 10\% Normal Donkey Serum (0.1 M TBS, 0.5\% Triton-X, $1 \mathrm{~h}$ ). Sections were then incubated with primary antibody (goat anti-doublecortin, $1: 3500$ ) in $0.1 \mathrm{M}$ TBS and $0.5 \%$ Triton-X at $4{ }^{\circ} \mathrm{C}$ overnight $(16 \mathrm{~h})$. Sections were rinsed with TBS, and secondary antibody (biotinylated donkey anti-goat, 1:500) was applied $(1 \mathrm{~h})$. Detection of the secondary antibody was enhanced using the Vectastain $\mathrm{ABC}$ Elite kit, followed by applying DAB. Sections were rinsed with TBS, mounted, dehydrated and delipidated, and coverslipped using Aqua Poly/Mount.

\section{Quantification}

In the irradiation experiment, brains were collected from six mice for each treatment group (vehicle/fluoxetine, and sham/X-ray). Two brains from the fluoxetine treatment groups (one sham, one X-ray) were lost due to poor perfusion quality. Data reported are the result of quantification of $\mathrm{BrdU}$ and $\mathrm{DCx}$ of the following numbers of brains: vehicle/sham 6, vehicle/X-ray 6 , fluoxetine/sham 5 , and fluoxetine/X-ray 5. BrdU- and DCx-postive cells in the subgranular zone of the dentate gyrus were quantified under $\times 63$ and $\times 40$ magnification, respectively, using a Zeiss Axiovert 200 microscope. Using the sectioning described above, six sets of sections from each brain are generated. Therefore, the number of positive cells for one set of sections (numbers of sections per group listed above) was multiplied by six to give an estimated number of total positive cells throughout the entire dentate gyrus.

\section{Statistical Analyses}

Data were analyzed using StatView 5.0 software. For all experiments, Analysis of Variance (ANOVA) was applied to the data. Significant interactions were resolved using post hoc ANOVAs with adjusted $p$-values and/or Newman-Keuls post hoc tests. In the FST, animals exhibiting immobility scores of greater than two SD from the mean were removed from the analysis. The level of significance was set to $p<0.05$. Analyses specific to each experiment are described in the Results. 


\section{RESULTS}

FST Specifically Detects Antidepressant Effects and Depends on Chronic Administration

For each experiment, separate two-way ANOVAs were applied with time bin ( 1 min intervals) as a within-subjects factor and drug as a between-subjects factor for each dependent measure (swimming, immobility, and climbing) and duration of treatment (2 or 28 days). As shown in Figure 1, chronic (28 days) but not subchronic (2 days), fluoxetine treatment significantly increased swimming $(\mathrm{F}(1,21)=4.684, \quad p<0.05)$ and decreased immobility $(\mathrm{F}(1,21)=6.785, p<0.05)$ in the FST in BALB/cJ mice. Chronic, but not subchronic, administration of the tricyclic antidepressant desipramine was also effective at reducing immobility $(\mathrm{F}(1,28)=5.840, p<0.05)$ and increasing climbing $(\mathrm{F}(1,28)=8.147, p<0.01)$. The dissociation between SSRIs and tricyclics to differentially affect the distinct active behaviors of swimming and climbing, respectively, has been reported previously (Detke et al, 1995). Additionally, we did not detect an effect of the antipsychotic haloperidol (1 mg/ $\mathrm{kg} /$ day) in the FST either when administered subchronically or chronically. Acute diazepam, a benzodiazepine, was not found to be effective at altering any behavior in the FST (data not shown).

We also verified that the mice in fact received expected levels of fluoxetine by examining the plasma levels of fluoxetine and the primary metabolite norfluoxetine using liquid chromatography with fluorescence detection (Suckow et al, 1992). Fluoxetine and norfluoxetine levels were found to be in the range expected of patients prescribed $20-80 \mathrm{mg}$ per day of fluoxetine (Koran et al, 1996; Supplementary Figure 1). Fluoxetine levels averaged $877.8 \mathrm{ng} / \mathrm{ml}$ (range: 573-1570) and the mean norfluoxetine level was $857.4 \mathrm{ng} / \mathrm{ml}$ (range: 538-1543).

\section{Time Course of Behavioral Effects}

Separate two-way ANOVAs were applied with time bin (1 min intervals) as a within-subjects factor and drug as a between-subjects factor for each dependent measure (swimming, immobility, and climbing) and duration of treatment $(2,12$, or 28 days). The behavioral effects of fluoxetine in the FST show a temporal dependence (Figure 2). Separate groups of mice were tested at each time point. Two days of fluoxetine treatment was insufficient to affect any of the dependent measures assessed (swimming: $\quad \mathrm{F}(1,22)=0.6986, \quad p>0.05$; $\quad$ immobility: $\mathrm{F}(1,22)=2.094, p>0.05)$. In contrast, significant effects of fluoxetine were present at 12 days of treatment (swimming: $\mathrm{F}(1,27)=9.298, \quad p<0.05 ; \quad$ immobility: $\mathrm{F}(1,27)=12.115$, $p<0.05)$. The effects of fluoxetine persisted at 28 days of treatment (swimming: $\mathrm{F}(1,22)=4.198, p<0.05$; immobility: $\mathrm{F}(1,22)=8.014, p<0.05)$.

\section{Contribution of Adult Hippocampal Neurogenesis to Fluoxetine-Induced Behaviors}

Mice underwent sham $(n=30)$ or irradiation $(n=30)$ treatment $(5 \mathrm{~Gy})$ on days 1,4 , and 7 of fluoxetine treatment (total: $15 \mathrm{~Gy}$ over 1 week). Mice were tested in the FST on days 30 and 31 of drug treatment. Data were analyzed using
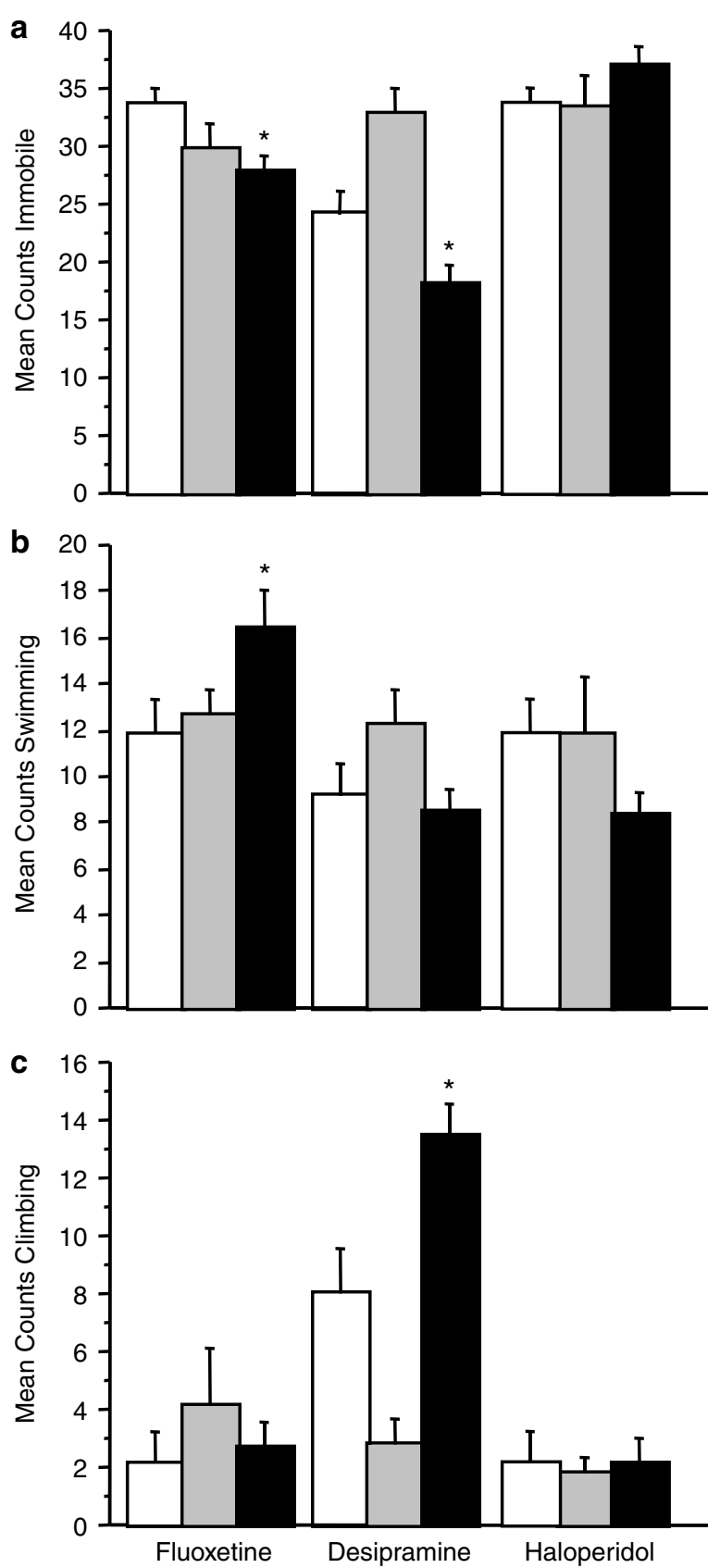

Figure I Temporal and pharmacological specificity of behavior in the forced swimming test. Mice were treated with vehicle (open bars), 2 days of drug treatment (gray bars), or 28 days of drug treatment (black bars). Separate experiments were conducted for each drug: fluoxetine ( $8 \mathrm{mg} / \mathrm{kg} /$ day), desipramine $(20 \mathrm{mg} / \mathrm{kg} /$ day $)$, and haloperidol ( $\mathrm{l} \mathrm{mg/kg/day).} \mathrm{The} \mathrm{data} \mathrm{are} \mathrm{shown} \mathrm{as} \mathrm{the} \mathrm{mean} \mathrm{counts} \mathrm{(a)} \mathrm{immobile,}$ (b) swimming, or (c) climbing for each drug experiment for the last four minutes of the six-minute test session ( $* 0<0.05$ vs vehicle group by ANOVA). $N=108$ ( $n=12$ per drug and duration).

a three-way ANOVA with time bin as a within-subjects factor, and drug (vehicle or fluoxetine) and irradiation condition (sham or X-ray) as between-subjects factors, with swimming, immobility, and climbing behavior analyzed by separate ANOVAs. As shown in Figure 3, chronic fluoxetine significantly reduced immobility $(\mathrm{F}(1,50)=51.896, p<0.05)$ in the FST. Immobility in the FST was unaltered by X-ray 

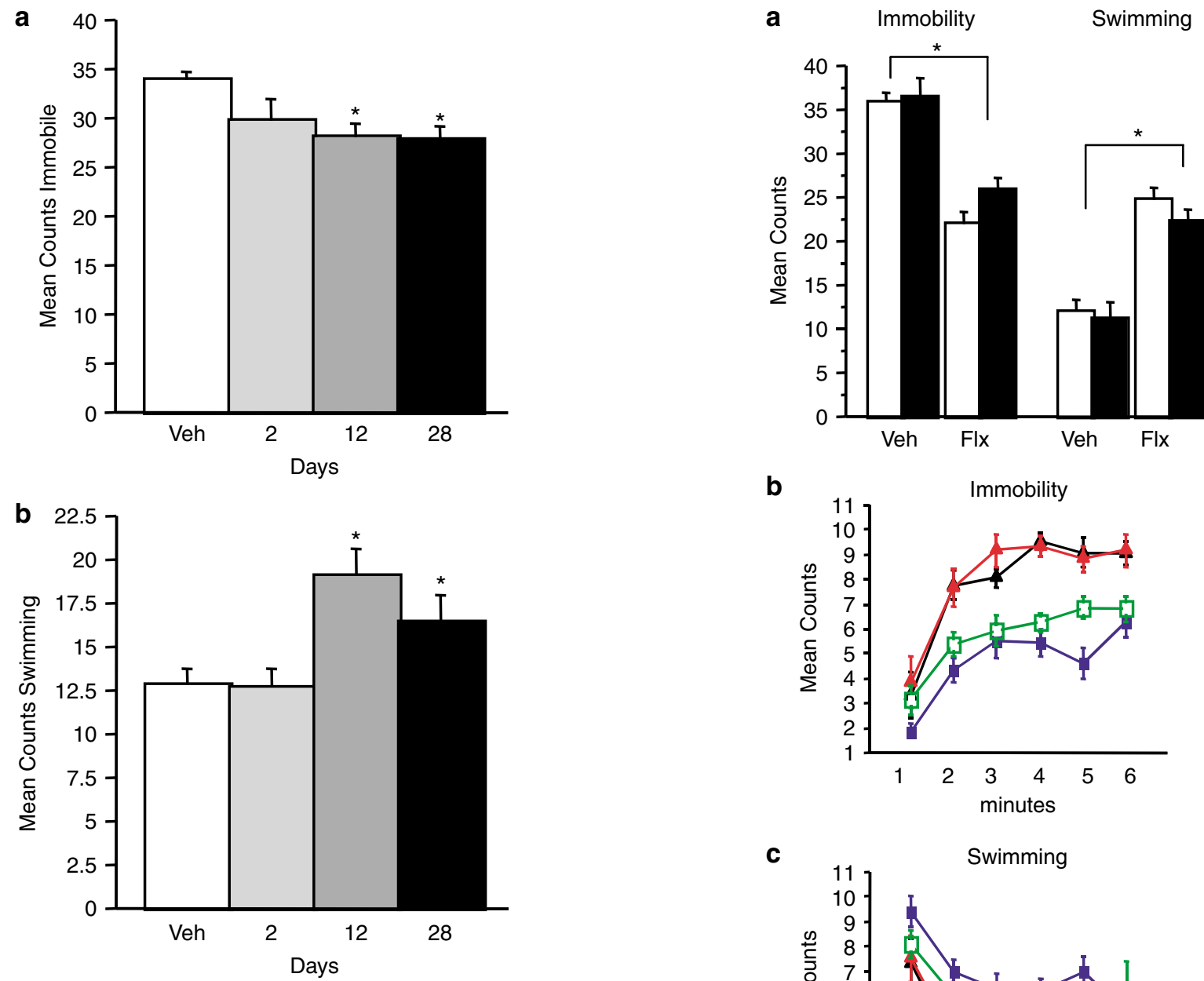

b

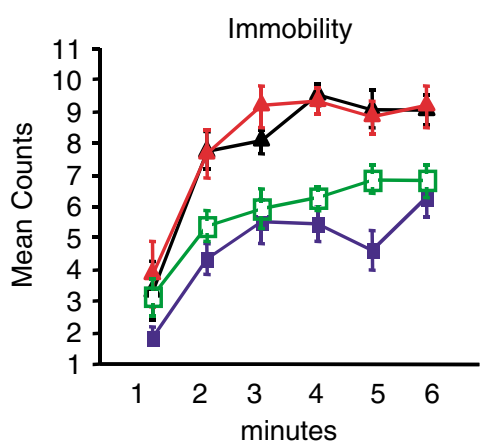

C

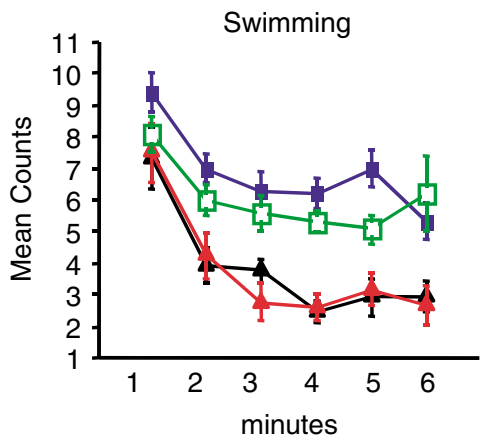

Figure 2 Time course of the behavioral effects of fluoxetine in the FST Separate groups of mice were used to assess the onset of the behavioral effects of fluoxetine in the FST. Mice were tested on days 2, 12 or 28 of fluoxetine treatment $(18 \mathrm{mg} / \mathrm{kg} /$ day); duration of treatment is indicated on the $x$ - axis. The vehicle groups from each experiment did not differ, so were thus pooled to generate a combined vehicle group from which data for mean counts immobile (a) and swimming (b) are shown ( ${ }^{2} p<0.05$ vs vehicle by ANOVA for each individual time point). 2 days: vehicle $n=12$, fluoxetine $n=12 ; 12$ days: vehicle $n=15$, fluoxetine $n=14 ; 28$ days: vehicle $n=12$, fluoxetine $n=12$.

irradiation $(F(1,50)=2.179, p>0.05)$. Additionally, irradiation did not alter the effect of fluoxetine on immobility in the FST $(F(1,50)=0.904, p>0.05)$. Similarly, swimming behavior was significantly increased by fluoxetine $(\mathrm{F}(1,50)=50.706, p<0.05)$, but neither a main effect of $\mathrm{X}$ ray irradiation $(\mathrm{F}(1,50)=1.414, p>0.05)$ nor an interaction $(\mathrm{F}(1,50)=1.020, p>0.05)$ were present.

\section{Immunohistochemistry}

We verified the successful ablation of progenitor cells by bromodeoxyuridine and doublecortin immunohistochemistry, and found that in both the vehicle- and fluoxetinetreated mice, irradiation dramatically reduced the number of BrdU-positive $(\mathrm{F}(1,18)=30.987, p<0.05)$ as well as doublecortin-positive $(\mathrm{F}(1,17)=66.622, p<0.05)$ cells as depicted in Figure 4. No doublecortin-positive cells were 

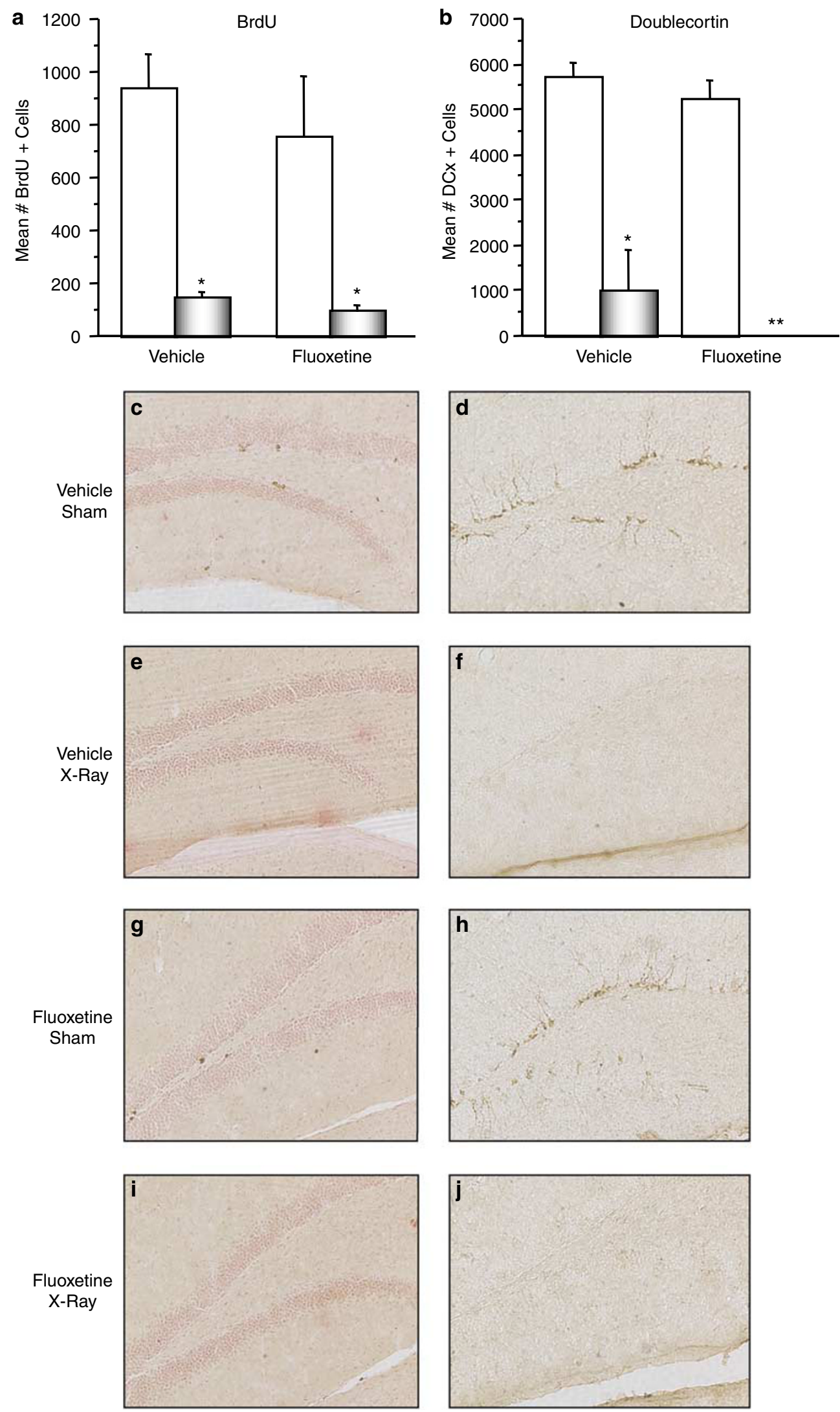

Figure 4 Immunohistochemistry of Cell Proliferation in the Dentate Gyrus of the Hippocampus. Mean number BrdU (a) and DCx (b) positive cells per brain ( $n=6$ per vehicle group, $n=5$ per fluoxetine group); open bars = sham, gray bars $=$ X-ray. Values are mean \pm SEM. * $p<0.05$ vs Sham for each drug group. **No DCx-positive cells were detected in any hippocampal sections for this group. (c-j) All images were taken at $\times 20$ magnification. Left panels (c, $\mathrm{e}, \mathrm{g}$, and i) are BrdU staining and right panels ( $d, f, h$, and j) are DCx staining. Images are from the following treatment conditions: vehicle/sham (c, d), vehicle/ X-ray (e, f), fluoxetine/sham (g, h), and fluoxetine/X-ray (i, j). 
the behavior in the FST is specifically neurogenesisindependent, or whether the use of the BALB/cJ strain as opposed to the $129 \mathrm{~Sv}$ strain yielded the different results. An independent group of $\mathrm{BALB} / \mathrm{cJ}$ mice did not show the expected fluoxetine-induced decrease in latency in the NSF (Supplementary Figure 2), thus impairing the use of this test to assess the contribution of neurogenesis as was used in the previous study. We therefore tested the BALB/cJ mice from the X-ray experiment in the novelty-induced hypophagia $(\mathrm{NIH})$ paradigm after FST testing. The NIH is a test we have recently developed (Dulawa et al, 2004), which, like the NSF, relies on the concept of hyponeophagia, or reduced consumption in a novel environment. As shown in Figure 5, $\mathrm{BALB} / \mathrm{cJ}$ mice respond to the novel environment with reduced consumption $(\mathrm{F}(1,27)=16.524, p<0.05)$ of sweetened condensed milk and a longer latency to drink the milk $(\mathrm{F}(1,27)=20.06, p<0.05)$ compared to the home cage environment. ANOVA revealed a significant interaction between drug treatment and environment for latency $(\mathrm{F}(2,27)=4.112, p<0.05)$. Subsequent Fisher's post hoc tests showed that $18 \mathrm{mg} / \mathrm{kg} /$ day of fluoxetine reverses the novelty-induced hypophagia on the latency measure $(p=0.027)$. As with the FST, the behavioral effects of chronic fluoxetine in the NIH were also unaltered by previous X-ray irradiation (environment by drug by X-ray ANOVA $(F(2,27)=0.354, p>0.05))$. Therefore, the effects of chronic fluoxetine in both the FST and the NIH in BALB/cJ mice were found to be neurogenesis-independent.

\section{Role of Serotonin 1A Receptor in Acute Antidepressant Effects in the FST}

Serotonin 1A receptor knockout mice (Ramboz et al, 1998) were backcrossed four generations from a 129Sv background onto a BALB/cJ background. The experimental mice were N4 congenic mice, containing greater than $90 \%$ of the

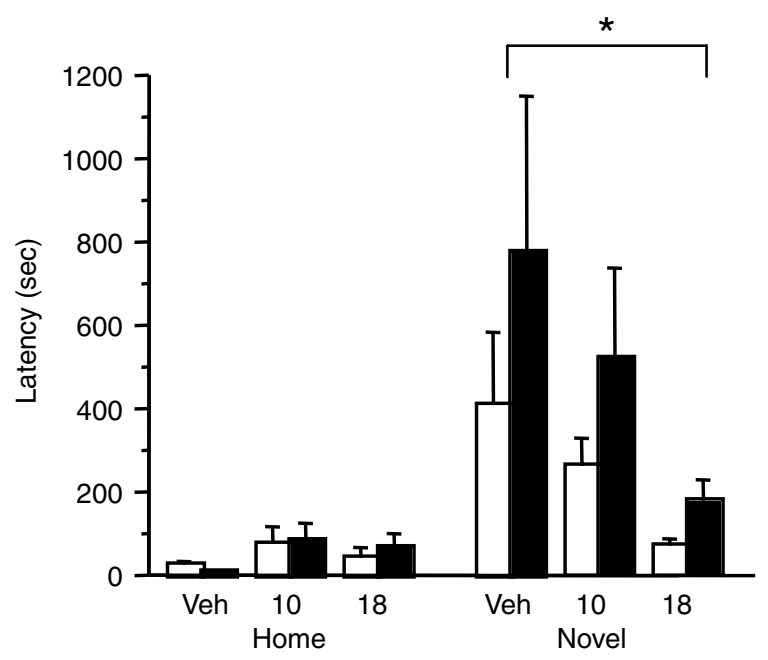

Figure 5 Effect of chronic fluoxetine in BALB/c) mice in the noveltyinduced hypophagia test. Mean latency to drink diluted sweetened condensed milk in the home and novel cages are shown $( \pm$ SEM) for mice treated with either sham (open bars) or X-ray (black bars). Mice were either treated with 0,10 , or $18 \mathrm{mg} / \mathrm{kg} /$ day fluoxetine in the drinking water. * $p<0.05$ for vehicle vs $18 \mathrm{mg} / \mathrm{kg} /$ day fluoxetine in the novel environment. genes of the BALB/CJ strain (Silver, 2005). A three-way ANOVA was used to assess the FST data from the $1 \mathrm{AKO}$ study with time bin as the within-subjects factor, and drug (vehicle, fluoxetine, or desipramine) and genotype (WT or $1 \mathrm{AKO}$ ) as between-subjects factors. Separate ANOVAs were used for the assessment of the effect of acute drug treatment on the three dependent measures of immobility, swimming, and climbing.

As shown in Figure 6, ANOVA evaluating the effects of acute fluoxetine treatment on immobility revealed a main effect of acute fluoxetine $(\mathrm{F}(1,20)=5.53, p<0.05)$, and a fluoxetine by genotype interaction $(\mathrm{F}(1,20)=8.18, p<0.01)$. Newman-Keuls post hoc tests indicated that vehicle-treated WT mice exhibited significantly more immobility than vehicle-treated $1 \mathrm{AKO}$ mice. Furthermore, acute fluoxetine treatment significantly reduced immobility in WT, but not $1 \mathrm{AKO}$ mice. ANOVA assessing the effects of acute fluoxetine treatment on swimming revealed a significant drug by genotype interaction $(\mathrm{F}(1,20)=4.43, p<0.05)$. Newman-Keuls post hoc tests showed that drug treatment significantly increased swimming in WT, but not $1 \mathrm{AKO}$ mice. Finally, ANOVA evaluating the effects of acute fluoxetine on climbing found a main effect of genotype on climbing $(\mathrm{F}(1,20)=5.32, p<0.05)$; thus, $1 \mathrm{AKO}$ mice exhibited more climbing behavior than WT mice across treatment conditions.

ANOVA evaluating the effects of acute desipramine on immobility revealed main effects of acute drug treatment $(\mathrm{F}(1,21)=7.87, p<0.01)$ and genotype $(\mathrm{F}(1,21)=4.58$, $p<0.05)$, and a drug by genotype interaction $(\mathrm{F}(1,21)=8.97, p<0.01)$. Newman-Keuls post hoc tests showed that acute desipramine treatment significantly reduced immobility in WT, but not $1 \mathrm{AKO}$ mice. No significant effects of acute desipramine treatment or genotype on swimming behavior were found. Finally, ANOVA assessing the effects of acute desipramine treatment on climbing found a main effect of drug $(\mathrm{F}(1,21)=5.40, \quad p<0.05)$, with desipramine increasing climbing behavior across genotypes.

\section{Role of Serotonin 1A Receptor in Chronic Antidepressant Effects in the FST}

ANOVA assessing the effects of chronic fluoxetine on immobility revealed a main effect for drug $(F(1,20)=10.74$, $p<0.01)$ to reduce immobility across both genotypes (Figure 7). A planned post hoc ANOVA evaluating the effect of genotype on immobility within vehicle-treated animals revealed a strong trend $(\mathrm{F}(1,12)=4.34, p=0.06)$ for $1 \mathrm{AKO}$ mice to exhibit reduced immobility compared to WT mice. No main effects or interactions of genotype and fluoxetine treatment on swimming were found. ANOVA evaluating the effects of chronic fluoxetine treatment on climbing revealed main effects of genotype $(\mathrm{F}(1,20)=5.42, p<0.05)$ and drug $(\mathrm{F}(1,20)=12.23, p<0.01)$, with chronic fluoxetine increasing climbing behavior in both genotypes, and $1 \mathrm{AKO}$ mice exhibiting more climbing behavior than WT mice overall.

As shown in Figure 7, ANOVA assessing the effects of chronic desipramine on immobility found a main effect of drug $(\mathrm{F}(1,20)=26.311, p<0.001)$, with desipramine reducing immobility across genotypes. Swimming behavior was unaffected by chronic desipramine treatment or genotype. 

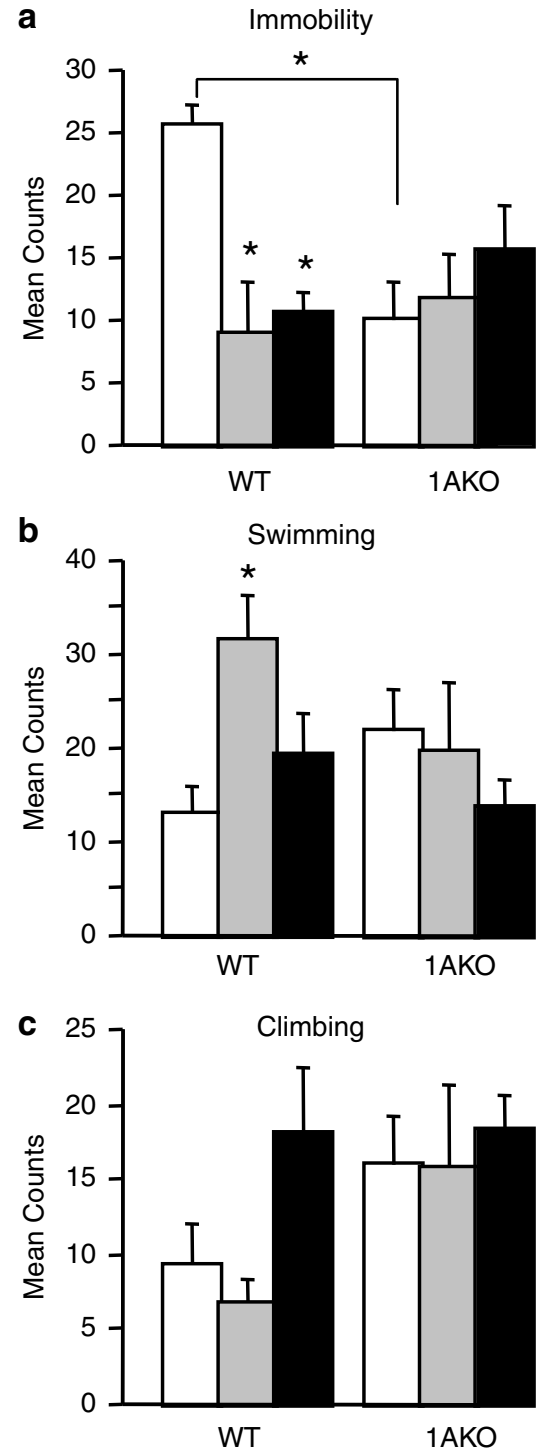

Figure 6 Effects of acute fluoxetine and desipramine in 5-HTIA receptor knock-out mice in the FST. Data are expressed as mean counts (a) immobile, (b) swimming, and (c) climbing ( \pm SEM; open bars = vehicle, gray bars = fluoxetine, $10 \mathrm{mg} / \mathrm{kg} /$ day, black bars = desipramine, $20 \mathrm{mg} / \mathrm{kg} /$ day). Drugs were administered as a single acute injection (i.p. in $0.9 \% \mathrm{NaCl}$ ) 30 min before testing. *Significant effects $(p<0.05)$ are indicated for Newman-Keuls post hoc analyses to reveal the specific significant comparisons from drug by genotype interactions. IAKO $n=18$; WT $n=15$.

A main effect of chronic desipramine treatment on climbing $(\mathrm{F}(1,20)=10.657, p<0.001)$ was also found, with desipramine increasing climbing behavior across genotypes.

\section{DISCUSSION}

Our present findings suggest that the FST provides a valid assessment of chronic antidepressant action in BALB/cJ mice. Furthermore, our findings that the serotonin $1 \mathrm{~A}$ receptor may be required for the behavioral response to acute, but not chronic, fluoxetine treatment in the FST suggest that different mechanisms underlie these effects.
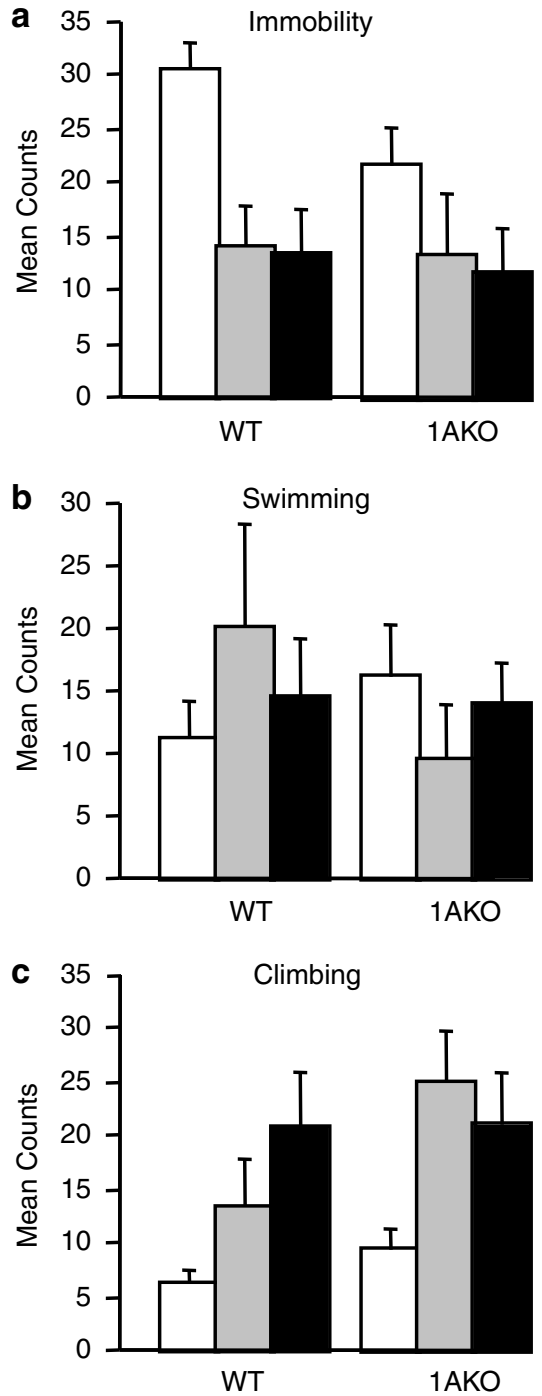

Figure 7 Effects of chronic fluoxetine and desipramine in 5-HTIA receptor knock-out mice in the FST. Data are expressed as mean counts (a) immobile, (b) swimming, and (c) climbing ( \pm SEM; open bars = vehicle, gray bars = fluoxetine, $10 \mathrm{mg} / \mathrm{kg} /$ day, black bars = desipramine, $20 \mathrm{mg} / \mathrm{kg} /$ day). Mice were tested after $2 \mathrm{I}$ days of chronic fluoxetine administration via drinking water.

The serotonin $1 \mathrm{~A}$ receptor does not appear to be required for the behavioral response to acute or chronic administration of the tricyclic desipramine. Finally, in contrast to previously published findings in the NSF test in the 129/Sv strain, our data show that the behavioral responses to chronic fluoxetine in the FST and in the NIH test are independent of adult hippocampal neurogenesis (see Table 1 for summary of findings). Our results suggest the presence of strain-dependent mechanisms underlying the antidepressant response.

The onset of the therapeutic effects of antidepressant drugs in patients exhibits a characteristic delay of several weeks (Andreoli et al, 2002; De Nayer et al, 2002; Blier, 2003). The traditional FST is a reliable assay with strong predictive validity for antidepressant compounds that assesses the behavioral response to acute drug treatment. However, due to the use of acute drug treatments, the 
Table I Summary of the Effects of Chronic Fluoxetine Administration by Strain and Behavioral Test

Effects of chronic fluoxetine

\begin{tabular}{lccc}
\cline { 2 - 4 } Strain & I29SvEvTac & BALB/cJ & BALB/c] \\
Test & NSF $^{\text {a }}$ & FST & NIH \\
\hline Stimulate neurogenesis & Yes & No & No \\
X-ray sensitive & Yes & No & No \\
Effective in IAKO & No & Yes & ND \\
\hline
\end{tabular}

ND, not determined.

aSantarelli et al (2003).

traditional FST cannot be used to study the mechanisms underlying the delayed onset of the therapeutic effects of antidepressants. Rather, a behavioral paradigm used for the purpose of identifying mechanisms of the antidepressant response should exhibit validity for the time course of drug action in patients. Here, we have shown that in BALB/cJ mice chronic, but not subchronic, administration of the SSRI fluoxetine and the tricyclic antidepressant desipramine increased active behavior and decreased immobility in the FST, while neither the antipsychotic haloperidol nor the benzodiazepine diazepam had significant behavioral effects. Thus, this chronic application of the FST offers a tool for studying the mechanisms underlying the antidepressant response.

\section{Time Course of Fluoxetine Effects in the FST}

The time course experiments assessed the onset of the behavioral effects of fluoxetine in the FST. We find that the effects on immobility and swimming are absent at two days of drug administration, appear at 12 days and persist through 28 days of treatment. Additionally, we have previously demonstrated that 7 days of fluoxetine administration is also insufficient to induce these behavioral changes in the FST in BALB/cJ mice (Dulawa et al, 2004). The behavioral response to fluoxetine that appears between 7 and 12 days of treatment likely results from slowly developing neural adaptations in response to sustained drug treatment.

While 2 days of fluoxetine administration in the drinking water was ineffective, a single intraperitoneal injection of fluoxetine effectively altered FST behavior (see Figure 6). The mechanisms underlying these acute behavioral changes are unlikely to be the same as those mediating the behavioral effects that emerge chronically. The route of administration (intravenous $v s$ oral) significantly impacts the pharmacokinetics of fluoxetine (Caccia et al, 1990). The acute behavioral effects may result from a sharp peak in blood levels of fluoxetine and its active metabolite norfluoxetine. The sustained fluoxetine administration in the drinking water produces a slow rise to steady state blood levels; this perhaps better mimics the administration to patients.

Clinically, the presence of a delayed onset of the antidepressant response has been debated. A recent metaanalysis of 28 randomized controlled trials shows evidence of antidepressant effects as early as 1 week after commencing treatment (Taylor et al, 2006). Additionally, new rodent data show that the time lag between antidepressant drug administration and behavioral testing is perhaps more important than sustained chronic dosing in the development of the antidepressant response (Kusmider et al, 2006). Nevertheless, clearly more robust effects emerge with time of treatment, and the behaviors observed here do present a delayed onset.

\section{Serotonin 1A Receptors and the Antidepressant Response}

On the BALB/cJ background, we replicated previously published findings indicating an antidepressant-like phenotype of the $1 \mathrm{AKO}$ in the tail suspension test (Mayorga et al, 2001) and in the FST (Ramboz et al, 1998). Specifically, the N4 BALB/cJ 1AKO congenic mice treated with vehicle exhibit less immobility than their wild-type counterparts. The $1 \mathrm{AKO}$ mice also do not respond to acute, but do appear to respond to chronic fluoxetine in the FST. Additionally, $1 \mathrm{AKO}$ mice respond to both acute and chronic treatment with the tricyclic antidepressant desipramine in the FST. Although we cannot exclude the possibility that the lack of effect of acute fluoxetine treatment on immobility in $1 \mathrm{AKO}$ mice is due to a floor effect, $1 \mathrm{AKO}$ mice did not show any increase in swimming behavior as observed in the wildtype mice. Both wild type and $1 \mathrm{AKO}$ mice clearly responded to chronic fluoxetine treatment in the FST.

Different neural mechanisms likely underlie the acute and chronic effects of antidepressants in the FST in the WT and $1 \mathrm{AKO}$ mice. We observed that both the WT and 1AKO mice respond to chronic treatment with fluoxetine or desipramine. Although much evidence now supports a role for the serotonin $1 \mathrm{~A}$ receptor in mediating the acute effects of fluoxetine in behavioral paradigms (ie, FST and TST), here we show for the first time that the serotonin $1 \mathrm{~A}$ receptor is not required for the chronic effects of antidepressants in the FST. It may be reasonable to speculate that the behavioral effects of acute fluoxetine in the FST capture early mechanisms of the antidepressant response that set into motion a cascade of events that culminate in the delayed therapeutic response in patients (Kusmider et al, 2006). However, in the FST, it appears that the acute effects are independent of the chronic behavioral effects. The 5-HT1A receptor-dependent acute behavioral effects are not likely to represent an initiating event that later develops into a chronic effect, since the 5-HT1A receptor does not appear to be needed for the effects of chronic fluoxetine in the FST.

Continued treatment with SSRIs has been suggested to alter the function of other neurotransmitter systems aside from serotonin. Some studies suggest that SSRIs augment noradrenergic, as well as serotonergic, function when given chronically (Page and Abercrombie, 1997; Thomas et al, 1998). Furthermore, fluoxetine exhibits moderate affinity for the norepinephrine transporter (NET) and very low affinity for the dopamine transporter (DAT) in humans (Owens et al, 2001). These reports are consistent with our finding that chronic fluoxetine treatment increased climbing behavior in the FST, which is typically observed following acute treatment with antidepressants that block NET. The behaviors observed after chronic treatment may 
therefore reflect a combination of the action of fluoxetine on both the serotonergic and noradrenergic systems. Future experiments using serotonin or catecholamine depletion (PCPA or AMPT, respectively) will determine whether increased serotonin or catecholamine levels underlie the effects of chronic fluoxetine in the FST.

\section{Adult Hippocampal Neurogenesis}

We also sought to determine the contribution of adult hippocampal neurogenesis to the observed behavioral effects induced by chronic fluoxetine in the FST. Our previous study in a different strain of mice (129SvEvTac) indicated that the effects of chronic fluoxetine in the novelty-suppressed feeding (NSF) paradigm not only require the 5-HT1A receptor, but are also neurogenesisdependent (Santarelli et al, 2003). However, our present findings show that X-ray irradiation did not alter the fluoxetine-induced behavioral changes in the FST or NIH in $\mathrm{BALB} / \mathrm{cJ}$ mice. As a result, we have concluded that the behavioral effects of chronic fluoxetine in $\mathrm{BALB} / \mathrm{cJ}$ mice are not dependent upon hippocampal neurogenesis in the dentate gyrus. Furthermore, we also found that chronic fluoxetine did not increase cell proliferation in the dentate gyrus of the same mice that showed a robust antidepressant response in the FST and NIH. This finding further uncouples the effects of SSRIs on cell proliferation from their antidepressant efficacy.

Although chronic fluoxetine alters behavior in both paradigms, the hyponeophagia-based paradigms, NSF and $\mathrm{NIH}$, and FST tests measure different aspects of the antidepressant response. Behavior in the hyponeophagia tests and the FST are differentially sensitive to anxiolytic and antidepressant compounds, respectively. The NSF and NIH tests are sensitive to pure anxiolytic drugs such as benzodiazepines, as well as to chronic treatment with SSRIs, which have both anxiolytic and antidepressant effects (Bodnoff et al, 1988). In contrast, benzodiazepines such as diazepam are inactive in the FST (data not shown), but antidepressants reliably alter this behavior (Figure 1). Due to findings to date, one may be tempted to suggest that the mechanisms by which SSRIs mediate anxiolysis require cell proliferation in the dentate gyrus, while those mechanisms underlying the antidepressant effects of SSRIs do not. However, we found the antidepressant response in the NIH test to be neurogenesis-independent in $\mathrm{BALB} / \mathrm{cJ}$ mice. Furthermore, a recent report showed that reduced anxiety-like behavior in the NSF test induced by enriched environment and exercise, strong stimulators of neurogenesis, was also unaffected by X-ray irradiation (Meshi et al, 2006), suggesting that hippocampal neurogenesis was not involved in this effect. Thus, our present findings and those of Meshi et al (2006) show that the antidepressant effects of SSRIs and environmental enrichment do not depend upon the stimulation of adult hippocampal neurogenesis in a number of paradigms, including the NSF, NIH, and FST.

Another important factor potentially accounting for the conflicting results of studies to date is the strain of mouse utilized. The importance of strain selection is discussed in a recent review (Jacobson and Cryan, 2007) that details strain differences in baseline and depression-related behavior. The neurogenesis-dependent effects of fluoxetine in the NSF test were found in the 129SvEvTac strain of mice (Santarelli et al, 2003), whereas the neurogenesis-independent effects shown here in the FST and $\mathrm{NIH}$ were found in the BALB/cJ strain. It is possible that the two strains utilize different cellular and molecular machinery to mediate the behavioral effects of chronic antidepressant treatment. Unfortunately, the $129 \mathrm{SvEv}$ mice exhibit hind-limb rigidity as a side effect of fluoxetine treatment, rendering the behavioral response to chronic fluoxetine in the FST confounded in this strain (Lucki et al, 2001).

We have also tested the mice on the $\mathrm{N} 4$ congenic BALB/cJ background in the NSF test, but did not find the expected fluoxetine-induced decrease in latency to feed in these mice (Supplementary Figure 2). Due to limitations of the use of the NSF (challenges in the control of food deprivation, limited reliability), we have recently developed a new hyponeophagia paradigm, the novelty-induced hypophagia (NIH) (Dulawa et al, 2004; Dulawa and Hen, 2005). We have found that this paradigm provides a more robust and reliable measure of hyponeophagia in mice (Dulawa and Hen, 2005). Using this test, we found that the anxiolytic effect of chronic fluoxetine treatment was neurogenesisindependent in $\mathrm{BALB} / \mathrm{cJ}$ mice (Figure 5). These data suggest that (1) BALB/CJ mice do not respond to fluoxetine in the NSF and/or the NSF is not reliable enough to detect these drug effects, and (2) the effects of fluoxetine in the NIH, a similar hyponeophagia paradigm, are also neurogenesisindependent in the BALB/cJ strain. These conclusions suggest that differences in the strains, rather than the behavioral tests, explain the discrepancies between our previous report (Santarelli et al, 2003) and the data presented here.

Others have examined whether strain differences exist in baseline or stress-induced changes in cell proliferation and survival in the dentate gyrus. Recent reports show that female mice of the BALB/C and a 129 substrain (129/SvJ) are quite similar on measures of neurogenesis including cell proliferation, survival, and neuronal differentiation, although the $129 / \mathrm{SvJ}$ mice show slightly less survival 4 weeks after BrdU injection (Kempermann et al, 1997). Interestingly, we find here that chronic fluoxetine treatment does not induce an increase in adult hippocampal neurogenesis in $\mathrm{BALB} / \mathrm{cJ}$ mice, even though an antidepressant response was observed in the FST and NIH tests. Consistent with our findings, chronic fluoxetine treatment has been reported to have a minimal effect on neurogenesis in unstressed BALB/cJ mice by others (Alonso et al, 2004). Our findings demonstrate that anxiolytic and antidepressant effects of chronic SSRI treatment can be exhibited by mice in the absence of increased hippocampal neurogenesis.

Underlying differences in the corticosterone response of the two strains may explain the presence of both neurogenesis-dependent and neurogenesis-independent behavioral effects of chronic antidepressants. It has recently been shown that disruption of the normal diurnal rhythm of corticosterone in rats inhibits the effects of fluoxetine on cell proliferation and neurogenesis in the dentate gyrus (Huang and Herbert, 2006). Additionally, mouse strain differences in the corticosterone response to systemic challenge, as well as to neurogenic and psychogenic stressors have been examined identifying BALB/c mice as perhaps the most sensitive strain (Shanks et al, 1990; 
Anisman et al, 2001; Hayley et al, 2001). Future studies may explore whether the corticosterone system is sufficiently different in $\mathrm{BALB} / \mathrm{cJ}$ mice so as to prevent the induction of cell proliferation in the dentate gyrus following fluoxetine treatment. Nevertheless, behavioral effects of chronic fluoxetine in the BALB/cJ mice in our study were found despite the lack of increase in cell proliferation, suggesting that adult hippocampal neurogenesis does not mediate these behavioral effects (see summary of findings in Table 1). In this context it is noteworthy that the first human study of the role of neurogenesis in depression and antidepressant treatment failed to find an association (Reif et al, 2006), although future clinical and/or post-mortem studies are warranted.

In conclusion, we find that the FST in $\mathrm{BALB} / \mathrm{cJ}$ mice is a pharmacologically valid measure of chronic antidepressant action that shows delayed onset of behavioral effects. We have shown that these behavioral effects are independent of both adult hippocampal neurogenesis and the function of the 5-HT1A receptor, which is in contrast with our previous report in a difference strain of mice (Santarelli et al, 2003). The BALB/cJ mice also displayed a neurogenesis-independent response to fluoxetine in the novelty-induced hypophagia test. The strain differences that we have uncovered here may have clinical relevance since responsiveness to antidepressants is variable among patients as well. It is possible, and perhaps likely, that those patients that respond to SSRIs do so through various underlying neural mechanisms. As knowledge regarding the myriad of effects of SSRIs in the brain continues to expand, it is imperative that future studies utilize rodent behavioral models sensitive to chronic antidepressant treatment to dissect which of these neural changes play a causal role in their behavioral effects.

\section{ACKNOWLEDGEMENTS}

This work was supported by NARSAD (RH), NIMH R01 MH068542 (RH), and NIH MH071555-01A1 (SD). We thank Dr Irwin Lucki and Dr David Leonardo for helpful discussions in the writing of this manuscript.

\section{REFERENCES}

Alonso R, Griebel G, Pavone G, Stemmelin J, Le Fur G, Soubrie P (2004). Blockade of $\mathrm{CRF}(1)$ or $\mathrm{V}(1 \mathrm{~b})$ receptors reverses stressinduced suppression of neurogenesis in a mouse model of depression. Mol Psychiatry 9: 278-286, 224.

Andreoli V, Caillard V, Deo RS, Rybakowski JK, Versiani M (2002). Reboxetine, a new noradrenaline selective antidepressant, is at least as effective as fluoxetine in the treatment of depression. J Clin Psychopharmacol 22: 393-399.

Anisman H, Hayley S, Kelly O, Borowski T, Merali Z (2001). Psychogenic, neurogenic, and systemic stressor effects on plasma corticosterone and behavior: mouse strain-dependent outcomes. Behav Neurosci 115: 443-454.

Belzung C, Griebel G (2001). Measuring normal and pathological anxiety-like behaviour in mice: a review. Behav Brain Res 125: 141-149.

Blier P (2003). The pharmacology of putative early-onset antidepressant strategies. Eur Neuropsychopharmacol 13: 57-66.

Blier P, de Montigny C, Chaput Y (1987). Modifications of the serotonin system by antidepressant treatments: implications for the therapeutic response in major depression. J Clin Psychopharmacol 7(Suppl 6): 24S-35S.

Bodnoff SR, Suranyi-Cadotte B, Aitken DH, Quirion R, Meaney MJ (1988). The effects of chronic antidepressant treatment in an animal model of anxiety. Psychopharmacology (Berlin) 95: 298-302.

Bouwknecht JA, Paylor R (2002). Behavioral and physiological mouse assays for anxiety: a survey in nine mouse strains. Behavorial Brain Res 136: 489-501.

Brown JP, Couillard-Despres S, Cooper-Kuhn CM, Winkler J, Aigner L, Kuhn HG (2003). Transient expression of doublecortin during adult neurogenesis. J Comparative Neurol 467: 1-10.

Caccia S, Cappi M, Fracasso C, Garattini S (1990). Influence of dose and route of administration on the kinetics of fluoxetine and its metabolite norfluoxetine in the rat. Psychopharmacology (Berlin) 100: $509-514$.

Caldarone BJ, Karthigeyan K, Harrist A, Hunsberger JG, Wittmack E, King SL et al (2003). Sex differences in response to oral amitriptyline in three animal models of depression in C57BL/6 J mice. Psychopharmacology (Berlin) 170: 94-101.

Castren E (2004). Neurotrophic effects of antidepressant drugs. Curr Opin Pharmacol 4: 58-64.

Costa e Silva JA (2004). From restoration of neuroplasticity to the treatment of depression: clinical experience. Eur Neuropsychopharmacol 14(Suppl 5): S511-S521.

Cryan JF, Lucki I (2000). Antidepressant-like behavioral effects mediated by 5-hydroxytryptamine(2C) receptors. J Pharmacol Exp Ther 295: 1120-1126.

Cryan JF, Page ME, Lucki I (2005). Differential behavioral effects of the antidepressants reboxetine, fluoxetine, and moclobemide in a modified forced swim test following chronic treatment. Psychopharmacology (Berlin) 182: 335-344.

De Nayer A, Geerts S, Ruelens L, Schittecatte M, De Bleeker E, Van Eeckhoutte I et al (2002). Venlafaxine compared with fluoxetine in outpatients with depression and concomitant anxiety. Int $J$ Neuropsychopharmacol 5: 115-120.

Detke MJ, Johnson J, Lucki I (1997). Acute and chronic antidepressant drug treatment in the rat forced swimming test model of depression. Exp Clin Psychopharmacol 5: 107-112.

Detke MJ, Wieland S, Lucki I (1995). Blockade of the antidepressant-like effects of 8-OH-DPAT, buspirone and desipramine in the rat forced swim test by $5 \mathrm{HT} 1 \mathrm{~A}$ receptor antagonists. Psychopharmacology (Berlin) 119: 47-54.

D'Sa C, Duman RS (2002). Antidepressants and neuroplasticity. Bipolar Disord 4: 183-194.

Dulawa SC, Hen R (2005). Recent advances in animal models of chronic antidepressant effects: The novelty-induced hypophagia test. Neurosci Biobehav Rev 29: 771-783.

Dulawa SC, Holick KA, Gundersen B, Hen R (2004). Effects of chronic fluoxetine in animal models of anxiety and depression. Neuropsychopharmacology 29: 1321-1330.

Encinas JM, Vaahtokari A, Enikolopov G (2006). Fluoxetine targets early progenitor cells in the adult brain. Proc Nat Acad Sci USA 103: 8233-8238.

Fuchs E, Flugge G, Czeh B (2006). Remodeling of neuronal networks by stress. Frontiers Biosci 11: 2746-2758.

Hayley S, Borowski T, Merali Z, Anisman H (2001). Central monoamine activity in genetically distinct strains of mice following a psychogenic stressor: effects of predator exposure. Brain Res 892: 293-300.

Hensler JG (2002). Differential regulation of 5-HT1A receptor-G protein interactions in brain following chronic antidepressant administration. Neuropsychopharmacology 26: 565-573.

Hirano K, Kimura R, Sugimoto Y, Yamada J, Uchida S, Kato Y et al (2005). Relationship between brain serotonin transporter binding, plasma concentration and behavioural effect of selective serotonin reuptake inhibitors. $\mathrm{Br}$ J Pharmacol 144: 695-702. 
Huang GJ, Herbert J (2006). Stimulation of neurogenesis in the hippocampus of the adult rat by fluoxetine requires rhythmic change in corticosterone. Biol Psychiatry 59: 619-624.

Jacobson LH, Cryan JF (2007). Feeling strained? Influence of genetic background on depression-related behavior in mice: a review. Behav Genet 37: 171-213.

Kampf-Sherf O, Zlotogorski Z, Gilboa A, Speedie L, Lereya J, Rosca $\mathrm{P}$ et al (2004). Neuropsychological functioning in major depression and responsiveness to selective serotonin reuptake inhibitors antidepressants. J Affective Disord 82: 453-459.

Kelliher P, Kelly JP, Leonard BE, Sanchez C (2003). Effects of acute and chronic administration of selective monoamine re-uptake inhibitors in the rat forced swim test. Psychoneuroendocrinology 28: 332-347.

Kempermann G, Kuhn HG, Gage FH (1997). Genetic influence on neurogenesis in the dentate gyrus of adult mice. Proc Nat Acad Sci USA 94: 10409-10414.

Koran L, Cain J, Dominguez R, Rush A, Theimann S (1996). Are fluoxetine plasma levels related to outcome in obsessivecompulsive disorder? Am J Psychiatry 153: 1450-1454.

Kreiss DS, Lucki I (1995). Effects of acute and repeated administration of antidepressant drugs on extracellular levels of 5-hydroxytryptamine measured in vivo. J Pharmacol Exp Ther 274: 866-876.

Kusmider M, Faron-Gorecka A, Dziedzicka-Wasylewska M (2006). Delayed effects of antidepressant drugs in rats. Behav Pharmacol 17: 641-649.

Le Poul E, Laaris N, Doucet E, Laporte AM, Hamon M, Lanfumey L (1995). Early desensitization of somato-dendritic 5-HT1A autoreceptors in rats treated with fluoxetine or paroxetine. Naunyn Schmiedeberg's Arch Pharmacol 352: 141-148.

Lucassen PJ, Muller MB, Holsboer F, Bauer J, Holtrop A, Wouda J et al (2001). Hippocampal apoptosis in major depression is a minor event and absent from subareas at risk for glucocorticoid overexposure. Am J Pathol 158: 453-468.

Lucki I, Dalvi A, Mayorga AJ (2001). Sensitivity to the effects of pharmacologically selective antidepressants in different strains of mice. Psychopharmacology (Berlin) 155: 315-322.

Malberg JE, Eisch AJ, Nestler EJ, Duman RS (2000). Chronic antidepressant treatment increases neurogenesis in adult rat hippocampus. J Neurosci 20: 9104-9110.

Mayorga AJ, Dalvi A, Page ME, Zimov-Levinson S, Hen R, Lucki I (2001). Antidepressant-like behavioral effects in 5-hydroxytryptamine(1A) and 5-hydroxytryptamine(1B) receptor mutant mice. J Pharmacol Exp Ther 298: 1101-1107.

Meshi D, Drew MR, Saxe M, Ansorge MS, David D, Santarelli L et al (2006). Hippocampal neurogenesis is not required for behavioral effects of environmental enrichment. Nat Neurosci 9: 729-731.

Miller MW, Nowakowski RS (1988). Use of bromodeoxyuridineimmunohistochemistry to examine the proliferation, migration and time of origin of cells in the central nervous system. Brain Res 457: 44-52.

Moser PC, Sanger DJ (1999). 5-HT1A receptor antagonists neither potentiate nor inhibit the effects of fluoxetine and befloxatone in the forced swim test in rats. Eur J Pharmacol 372: 127-134.

Muller MB, Lucassen PJ, Yassouridis A, Hoogendijk WJ, Holsboer F, Swaab DF (2001). Neither major depression nor glucocorticoid treatment affects the cellular integrity of the human hippocampus. Eur J Neurosci 14: 1603-1612.

Owens MJ, Knight DL, Nemeroff CB (2001). Second-generation SSRIs: human monoamine transporter binding profile of escitalopram and R-fluoxetine. Biol Psychiatry 50: 345-350.
Page ME, Abercrombie ED (1997). An analysis of the effects of acute and chronic fluoxetine on extracellular norepinephrine in the rat hippocampus during stress. Neuropsychopharmacology 16: 419-425.

Porsolt RD, Bertin A, Blavet N, Deniel M, Jalfre M (1979). Immobility induced by forced swimming in rats: effects of agents which modify central catecholamine and serotonin activity. Eur J Pharmacol 57: 201-210.

Ramboz S, Oosting R, Amara DA, Kung HF, Blier P, Mendelsohn M et al (1998). Serotonin receptor 1A knockout: an animal model of anxiety-related disorder. Proc Nat Acad Sci USA 95: 1447614481.

Redrobe JP, Bourin M (1998). Dose-dependent influence of buspirone on the activities of selective serotonin reuptake inhibitors in the mouse forced swimming test. Psychopharmacology (Berlin) 138: 198-206.

Redrobe JP, MacSweeney CP, Bourin M (1996). The role of 5-HT1A and $5-\mathrm{HT} 1 \mathrm{~B}$ receptors in antidepressant drug actions in the mouse forced swimming test. Eur J Pharmacol 318: 213-220.

Reif A, Fritzen S, Finger M, Strobel A, Lauer M, Schmitt A et al (2006). Neural stem cell proliferation is decreased in schizophrenia, but not in depression. Mol Psychiatry 11: 514-522.

Reneric JP, Bouvard M, Stinus L (2002). In the rat forced swimming test, chronic but not subacute administration of dual 5-HT/NA antidepressant treatments may produce greater effects than selective drugs. Behav Brain Res 136: 521-532.

Robertson HA (1979). Benzodiazepine receptors in 'emotional' and 'non-emotional' mice; comparison of four strains. Eur J Pharmacol 56: 163-166.

Santarelli L, Saxe M, Gross C, Surget A, Battaglia F, Dulawa S et al (2003). Requirement of hippocampal neurogenesis for the behavioral effects of antidepressants. Science 301: 805-809.

Scott BW, Wojtowicz JM, Burnham WM (2000). Neurogenesis in the dentate gyrus of the rat following electroconvulsive shock seizures. Exp Neurol 165: 231-236.

Shanks N, Griffiths J, Zalcman S, Zacharko RM, Anisman H (1990). Mouse strain differences in plasma corticosterone following uncontrollable footshock. Pharmacol, Biochem, and Behav 36: 515-519.

Silver L (2005). Mouse Genetics: Concepts and Applications. Oxford University Press: Bar Harbor, ME.

Suckow RF, Zhang MF, Cooper TB (1992). Sensitive and selective liquid-chromatographic assay of fluoxetine and norfluoxetine in plasma with fluorescence detection after precolumn derivatization. Clin Chem 38: 1756-1761.

Tang X, Orchard SM, Sanford LD (2002). Home cage activity and behavioral performance in inbred and hybrid mice. Behav Brain Res 136: 555-569.

Taylor MJ, Freemantle N, Geddes JR, Bhagwagar Z (2006). Early onset of selective serotonin reuptake inhibitor antidepressant action: systematic review and meta-analysis. Archives Gen Psychiatry 63: 1217-1223.

Thomas DN, Nutt DJ, Holman RB (1998). Sertraline, a selective serotonin reuptake inhibitor modulates extracellular noradrenaline in the rat frontal cortex. J Psychopharmacol 12: 366-370.

van Praag H, Kempermann G, Gage FH (1999). Running increases cell proliferation and neurogenesis in the adult mouse dentate gyrus. Nat Neurosci 2: 266-270.

van Praag H, Schinder AF, Christie BR, Toni N, Palmer TD, Gage FH (2002). Functional neurogenesis in the adult hippocampus. Nature 415: 1030-1034.

Yu CC, Woods AL, Levison DA (1992). The assessment of cellular proliferation by immunohistochemistry: a review of currently available methods and their applications. Histochem J 24: 121-131. 